\title{
EFFECT OF MERCURIALS ON THE MEMBRANE PROTEIN OF RAT ERYTHROCYTES
}

\author{
Reiko TANAKA \\ Department of Pharmacology, Akita University School of Medicine, \\ Akita 010, Japan
}

Accepted June 15, 1978

\begin{abstract}
The membrane protein of rat erythrocytes, solubilized by $1 \%$ sodium dodecyl sulfate, was analyzed by polyacrylamide gel electrophoresis. Six major protein bands (Coomassie brilliant bluc positive, I-VI, molccular weight: 200,000, 170,000, 105,000, $96,000,80,000$ and 54,000 ) or three glycoprotein bands (PAS positive, 1-3, molecular weight: $108,000,96,000$ and 54,000 ) were detected in the membrane produced by hypotonic hemolysis. Several additional protein bands (between 90,000-40,000 molecular weight) were detected in the membrane produced by mercuric chloride, methylmercuric chloride and $\mathrm{N}$-ethylmaleimide hemolysis. A smaller number of bands $(90,000 \quad 40,000$ molecular weight) were detected in the membrane produced by p-chloromercuribenzoic acid hemolysis than the membrane hemolyzed by other mercurials. However, those additional bands did not appear when membranes were produced by hypotonic hemolysis then treated with mercurials. A band under band IV appeared when $p$-chloromercuribenzoic acid was used for the treatment. The profile of PAS positive bands of membrane produced by mercurial hemolysis was similar to that of membrane produced by hypotonic hemolysis. The degree of free sulfhydryl groups in membrane treated with mercurials was not closely related to the induction of hemolysis.
\end{abstract}

The hemolysis and morphological changes with mercurials (mercuric chloride, methylmercuric chloride, $p$-chloromercuribenzoic acid) in rat erythrocytes have been reported in previous papers $(1,2)$. In the present work, the effects of these mercurials on the membrane protein were investigated by protein analysis with SDS-polyacrylamide gel electrophoresis and measurement of sulfhydryl groups.

\section{MATERIALS AND METHODS}

\section{Preparation of membrane}

Blood samples were freshly collected from male rats (Sprague-Dawley strain) using heparin as the anticoagulant. After the three washings with phosphate buffered saline (PBS; pH 7.4), crythrocytes were lysed completely with hypotonic buffer (PB: $10 \mathrm{mM}$, $\mathrm{pH}$ 7.4), mercurials or other chemicals within $60 \mathrm{~min}$ at $37^{\circ} \mathrm{C}$. Mercurial solutions were prepared as described in the previous paper (1). Saponin (Wako Pure Chemical Industries), digitonin (Merck), lysolecithin (Sigma), Triton X-100 (Wako Pure Chemical Industries) and N-ethylmaleinide (NEM, Nakarai Chemicals) were dissolved in PBS.

Collected membranes were washed three times with PB (membranes lysed with PB) or with PBS (membranes lysed with mercurials and other chemicals) using a refrigerated centrifuge $(10,000 \mathrm{G}, 15 \mathrm{~min})$. 


\section{Protcin assay}

The membranc protein was determined by the method of Lowry et al (3) after solubilization in $1 \mathrm{~N} \mathrm{NaOH}$ for 45 min. Bovine albumin (albumin stock standard, Daiichi Pure Chemicals) was used as a protein standard.

\section{Treatment of membrane with mercurials}

Rat erythrocytes (2\% of final concentration) or membrane $(0.5 \mathrm{mg}$ protein) were incubated with mercuric chloride $\left(\mathrm{HgCl}_{2}\right.$, Wako Pure Chemical Industries), methylmercuric chloride (MMC, Wako Pure Chemical Industries), p-chloromercuribenzoic acid (PCMB, Wako Pure Chemical Industries) and PBS (control) for $60 \mathrm{~min}$ at $37^{\circ} \mathrm{C}$. After three washings with PBS, erythrocytes were lysed with PB. The membranes washed with PB or PBS as described above were prepared for SDS-polyacrylamide gel electrophoresis or for the measurement of the sulfhydryl groups.

To determine the distribution of MMC in membrane protein, erythrocytes were lysed with ${ }^{14} \mathrm{C}$ labeled MMC (New England Nuclear) or membranes produced by hypotonic lysis were incubated with ${ }^{14} \mathrm{C}$ labeled MMC. Radionctivity of ${ }^{14} \mathrm{C}$ in $2 \mathrm{~mm}$ slice of gel was measured with a liquid scintillation spectrometer (Mark II, NUCLEAR, CHICAGO), using $10 \mathrm{ml}$ of Bray's scintillation medium.

\section{Polyacrylamide gel electrophoresis}

SDS-polyacrylamide gel electrophoresis was employed by the method of Fairbanks et al (4). Glass tubes $7 \mathrm{~cm}$ long and with a $0.5 \mathrm{~cm}$ inside diameter were used. Acrylamide concentration was $5.6 \%$. Erythrocyte membranes $(0.5 \mathrm{mg}$ protein/ml) were dissolved in the following (final concentration): $1.0 \%$ sodium dodecyl sulfate, $10.0 \%$ sucrose, $10 \mathrm{mM}$ Tris-HCl (pH 8.0), 1 mM EDTA (pH 8.0) and $10 \mu \mathrm{g} / \mathrm{ml}$ pyronin $\mathrm{Y}$ (tracking dye). $100 \mu \mathrm{g}$ protein of membrane was added to each tube. When dithiothreitol (40 mM, Nakarai Chemicals) or 2-mercaptoethanol (130 mM, Tokyo Kasai Organic Chemicals) were added, samples were incubated for $10 \mathrm{~min}$ at $90^{\circ}-100^{\circ} \mathrm{C}$. Electrophoresis was performed with $5 \mathrm{~mA} /$ tube for $95 \mathrm{~min}$ at a room temperature of about $23^{\circ} \mathrm{C}$.

The gels were stained with Coomassie brilliant blue for protein or with periodic-Schiff reagent (PAS) for carbohydrate. Protein distribution were measured by optical absorption at $570 \mathrm{~nm}$ using a Densitron model-PAN (Jookoo Sangyo). Cytochrome C (Sigma), egg albumin (Sigma) and bovine serum albumin (Sigma) were used as molecular weight standards.

\section{Sulfhydryl group measurement}

Sulfhydryl groups (SH) in erythrocyte membrane were measured by the method of Sedlak and Lindsay (5) with Ellman's reagent. A $0.1 \mathrm{ml}$ of $0.01 \mathrm{M}$ DTNB [5,5'-dithiobis(2-nitrobenzoic acid) in absolute methyl alcohol, Wako Pure Chemical Industries] was added to the $1.5 \mathrm{ml}$ of membrane suspension ( $0.5 \mathrm{mg}$ protein in $0.2 \mathrm{M}$ Tris buffer, $\mathrm{pH} \mathrm{8.2).After}$ mixing with $1.0 \mathrm{ml}$ of absolute methyl alcohol, samples were allowed to stand with occasional shaking for $15 \mathrm{~min}$ and then centrifugated $(1,500 \mathrm{G}, 5 \mathrm{~min})$. Within $30 \mathrm{~min}$ after the addition of DTNB, optical absorbance of the supernatant was measured at $412 \mathrm{~nm}$. 


\section{RESULTS}

SDS-polyacrylamide gel electrophoresis

Six major protcin bands were identified in hypotonic lysed membrane of rat erythrocyte by SDS-polyacrylamide gel electrophoresis and Coomassie brilliant blue staining. The molecular weights of those protein bands were assumed to be $200,000,170,000,105,000$, 96,000, 80,000 and 54,000. With PAS staining, four carbohydrate bands (PAS 1-4, molecular weight: $108,000,96,000,54,000$ and $<15,000)$ were detected. The positions of PAS I, 2 and 3 corresponded to the positions of protein band III, IV and VI, respectively; however protein was not detected in the position of band PAS 4 (Fig. 1).

Electrophoretic patterns of membrane protein produced by mercurials and other chemicals are shown in Fig. 2. Protein bands of membrane produced by $\mathrm{HgCl}_{2}, \mathbf{M M C}$ and NEM were separated to band I-IV and several additional bands in the range of $90,000-$ 40,000 of molecular weight but it was difficult to detect bands V and VI. Protein bands of membrane produced by PCMB were somewhat different from that of membrane produced by other mercurials as there was a smaller number of bands in the range of $90,000-40,000$ of molecular weight (indicated by - in Fig. 2). Membranes produced by saponin, digitonin, lysolecithin and Triton X-100 showed the same protein patterns as that of membrane produced by the hypotonic buffer.

Electrophoretic patterns of PAS positive substances of membranes produced by mercurials, NEM, saponin, digitonin, lysolecithin and Triton X-100 were similar to that of membrane produced by hypotonic buffer. Those Coomassie brilliant blue positive and PAS positive patterns were not allered by treatment of the membrane solutions with dithiothreitol or 2-mercaptocthanol.

By treatment with $\mathrm{HgCl}_{2}, \mathrm{MMC}$ and NEM, protein patterns of membranc produced by hypotonic buffer were not changed; however, when treated with PCMB, the appearence of a new band (indicated by -- ) under band IV occurred as shown in Fig. 3.

Protein pattern of membrane produced by hypotonic buffer from the erythrocytes treated with nonhemolytic concentration of mercurials was similar to that of hypotonic lysed membrane, but when erythrocytes were treated with a

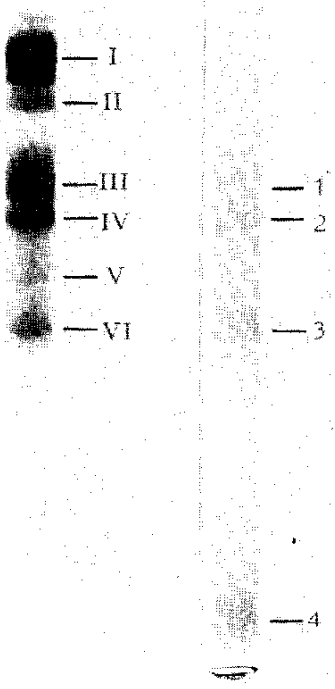

FiG. 1. SDS-polyacrylamide gel electrophoresis of rat erythrocyte membrane produced by hypotonic lysis. Left gel: Coomassie brilliant blue staining. Right gel: periodic acid-Schill reagent staining. Molecular weight (assumed)

\begin{tabular}{|c|c|c|}
\hline I & 200,000 & $1 \quad 108,000$ \\
\hline II & 170,000 & 96,000 \\
\hline III & 105,000 & 54,000 \\
\hline IV & 96,000 & $4<15,000$ \\
\hline$\gamma$ & 80,000 & \\
\hline & 54,000 & \\
\hline
\end{tabular}




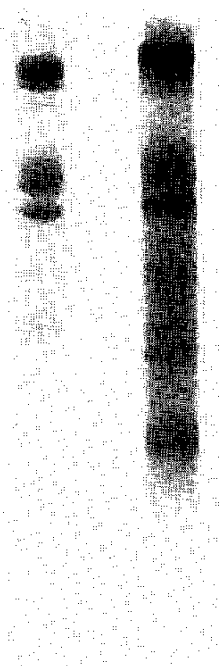

(a)

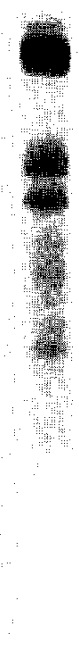

(c)

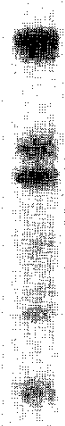

(d)
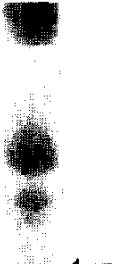
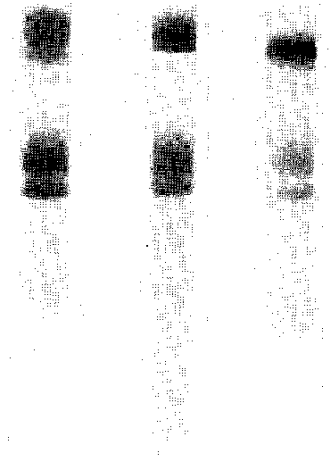

(g)

(h)

Fig. 2. SDS-polyacrylamide gel electrophoresis of rat erythrocyle membrane (Coomassie brilliant blue staining). Membranes were produced by lysis with hypotonic buffer (a) mercuric chloride (b), methylmercuric chloride (c), $\mathrm{N}$-ethylmaleimide (d), p-chloromercuribenzoic acid (c), saponin ( $\mathrm{f}$ ), digitonin (g), lysolecithin (h) and Triton X-100 (i). The bands in the range of 90,000-40,000 of molecular weight are indicated by --.

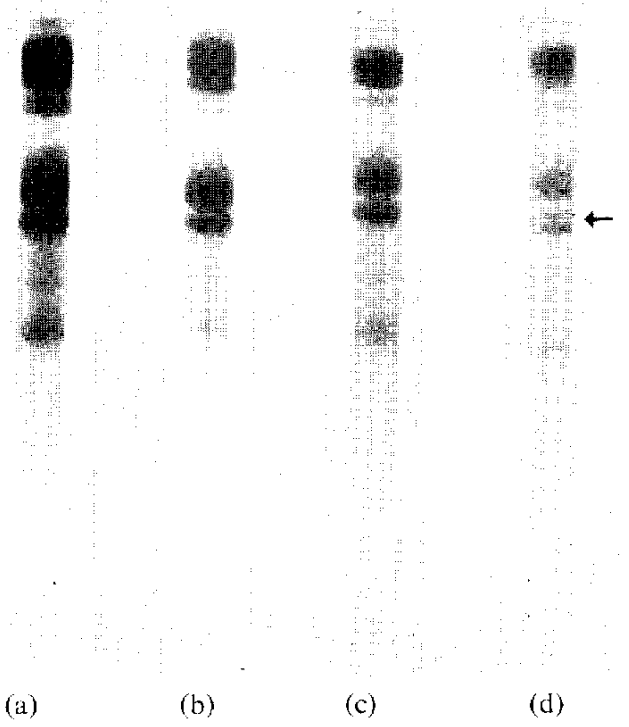

FIG. 3. SDS-polyacrylamide gel electrophoresis of rat erythrocyte membrane (Coomassie brilliant blue staining). Membranes $(0.5 \mathrm{mg}$ protcin) produced by hypotonic lysis were treated with $5 \mathrm{mM}$ mercurials and PBS for $60 \mathrm{~min}$ at $37 \mathrm{C}$. Treatment: (a) PBS (control) (b) mercuric chloride (c) methylmercuric chloride (d) p-chloromercuribenzoic acid. New band by PCMB treatment is indicated by $\leftarrow$ in $(d)$. 
slightly hemolytic concentration of mercurials, the protein pattern was similar to that of mercurial lysed membrane.

The protein patten of membrane treated with MMC is shown in Fig. 4. The erythrocytes treated with $0.1 \mathrm{mM}$ $\mathrm{MMC}$ for $60 \mathrm{~min}$ at $37^{\circ} \mathrm{C}$ were not lysed and the protein pattern of membranc produced by hypotonic lysis was similar to that of membrane produced by hypotonic lysis from nontreated erythrocytes. However erythrocytes treated with $0.15 \mathrm{mM}$ MMC for 60 min at $37^{\circ} \mathrm{C}$ were slightly lysed and membrane produced by hypotonic lysis showed the same characteristic protein pattern (indicated by $\leftarrow$ ) as MMC lysed membrane.

Distribution of methylmercuric chloride in membrane protein

Scanning patterns of ${ }^{14} \mathrm{C}$ and protein (stained with Coomassie brilliant blue) of gels analyzed by SDS-polyacrylamide gel electrophoresis are shown in Fig. 5.

In the membrane produced by hypotonic buffer and then treated with ${ }^{14} \mathrm{C}$ labeled $\mathrm{MMC}$, ${ }^{1+} \mathrm{C}$ was detected in the protein bands I-VI (left gel). In the membrane produced by $\mathrm{C}^{14}$ labeled $\mathrm{MMC},{ }^{14} \mathrm{C}$ was detected most in protein band $\mathrm{III}$ and to some extent in the other bands (right gel).

\section{Sulfhydryl groups in membrane}

1) Rat erythrocytes were incubated with mercurials, NEM and PBS (control) for 60 min at $37^{\circ} \mathrm{C}$. After the lysis with hypotonic buffer, $\mathrm{SH}$ in the membrane was measured. As shown in Fig. 6, at the prehemolytic concentration of $\mathrm{HgCl}_{2}(0.02 \mathrm{mM})$, MMC $(0.5 \mathrm{mM})$, and PCMB $(0.1 \mathrm{mM})$, SH was $77.5 \%, 37.0 \%$ and $98.5 \%$ of control, respectively. $\mathrm{SH}$ in membrane lysed completely with $\mathrm{HgCl}_{2}, \mathrm{MMC}, \mathrm{PCMB}$ and $\mathrm{NEM}$ was $17.4 \%, 17.4 \%, 60.9 \%$ and $13.0 \%$ of control, respectively. Time courses of $\mathrm{SH}$ decreasing with $\mathrm{HgCl}_{2}, \mathrm{MMC}$ and NEM treatment are shown in Fig. 7. In the first period of $10 \mathrm{~min}$, decrease in SH was rapid and decreasing curves after $\mathrm{HgCl}_{2}$ and $\mathrm{MMC}$ treatment were in parailel to that seen after NEM.

2) $\mathrm{SH}$ in hypotonic lysed membrane was decreased by treatment with mercurials and NEM. At the concentration of $1 \mathrm{mM} \mathrm{HgCl}_{2}, \mathrm{MMC}, \mathrm{PCMB}$ and $\mathrm{NEM}, \mathrm{SH}$ in membrane was estimated to be $3.0 \%, 40.0 \%, 24.0 \%$ and $49.0 \%$ of control, respectively. At the con- 


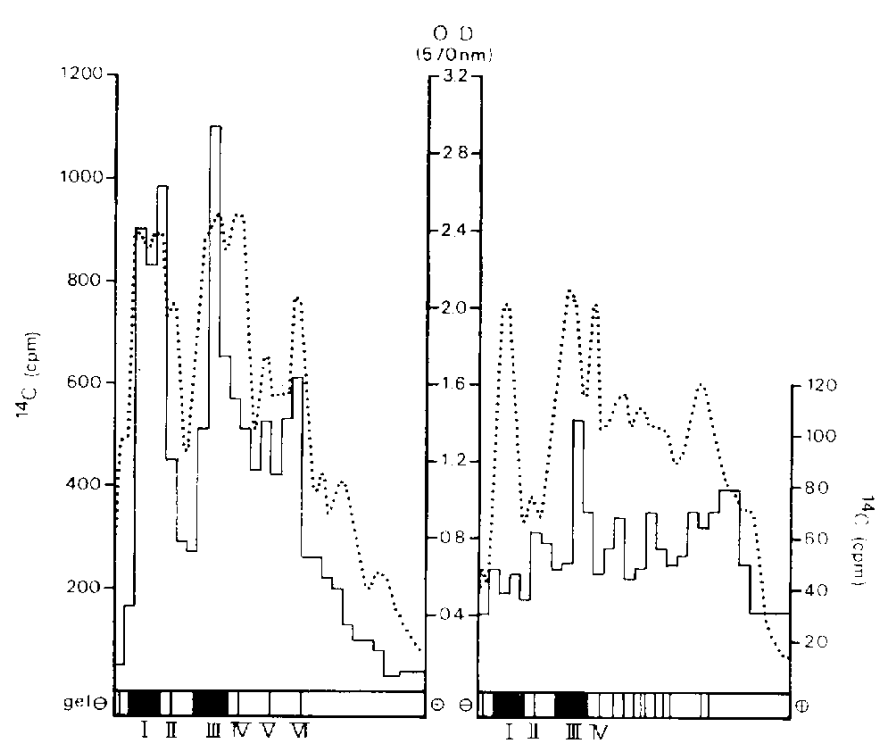

Fici. 5. Distribution of methylmercuric chloride in membrane protein.

Left gel: Membranes $(0.5 \mathrm{mg}$ protein) produced by hypotonic lysis were treated with $10 \mathrm{mM}$ MMC (contained $4 \mathrm{C}$ labeled MMC) for $60 \mathrm{~min}$ at $37 \mathrm{C}$. After the washing with phosphate buffer, membrane protein was analyzed by SDSpolyacrylamide gel electrophoresis. Protein was scanned at $570 \mathrm{~m} n$ after the staining with Coomassie brilliant blue. and radioactivity of : $\mathrm{C}$ was measured in $2 \mathrm{~mm}$ slices of gel using the scintillation method

Right gel: Rat erythrocytes were lysed with $0.3 \mathrm{mM}$ MMC (contained $\mathrm{C}$ labeled MMC) at $37 \mathrm{C}$. After the separation of membrane, protein was analyzed by SDS-polyacrylamide gel electrophoresis. Protein and radioactivily of ${ }^{1} \mathrm{C}$ were measured as described above.

centration of $10 \mathrm{mM} \mathrm{MMC} \mathrm{and} \mathrm{NEM,} \mathrm{SH} \mathrm{was} 2.0 \%$ and $49.5 \%$ of control, and a pH of $10 \mathrm{mM}$ PCMB solution proved to be too high to incubate the membrane.

\section{DISCUSSION}

Fairbanks ef al (4) demonstrated that human erythrocyte membrane obtained hypotonically could be separated into six major bands by Coomassie brilliant blue staining and four bands by PAS staining with SDS-polyacrylanide gel electrophoresis. In this work. rat erythrocyte membrane obtained hypotonically was separated into six major protein bands and four PAS positive bands; however molecular weight of each band differed from that of human erythrocyte membrane.

In the study of human erythrocyte membrane by Steck (6), it was assumed that band I was the speetrin like protein which constitutes inside of the membrane and band III was the protein penetrated through the membrane. In rat erythrocytes, if band $I$ is the protein constituted inside of the membrane and band $\mathrm{III}$ is the protein which penetrates through the membrane, the high distribution of ${ }^{1+C}$ labeled MMC in band III of MMC lysed membrane, indicates at greater binding of MMC to outside of erythrocyte membrane than inside of it: however each band has high affinity to MMC (Fig. 5). In the membranes produced by 


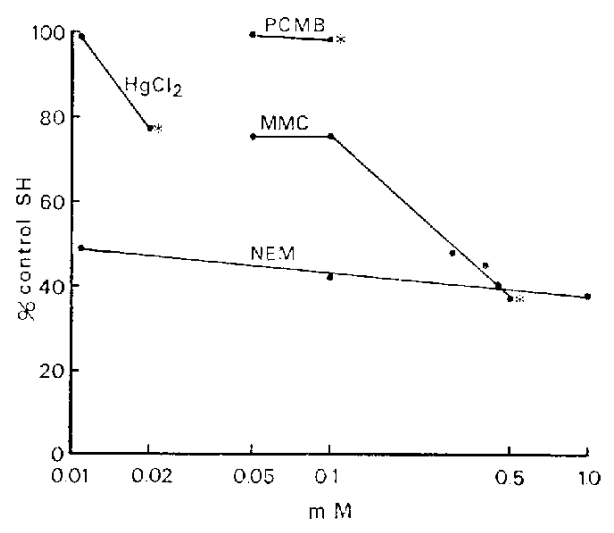

FiG. 6. Sulfhydryl groups in rat erythrocyte membrane. Erythrocytes were treated with each concentration of the mcrcurials, N-ethylmaleimide and PBS (control) for 60 min at $37^{\circ} \mathrm{C}$. Hemolysis was observed at above the point of concentration. Concentration of erythrocytes was $2.0 \%$. After the washing with PBS and lysis with hypotonic buffer, sulfhydryl groups in the membrane were measured.

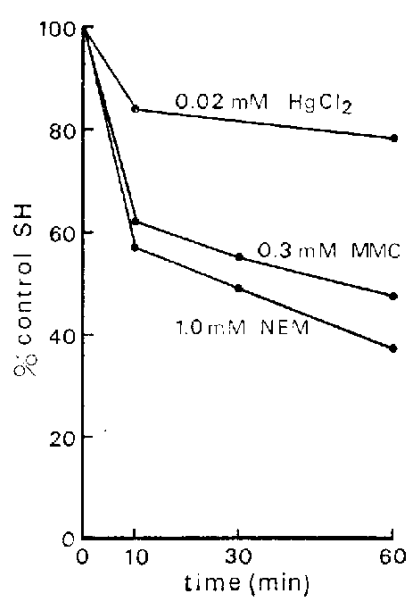

FIG. 7. Time course of decrease of sulfhydryl groups in membrane. Rat erythrocytes were treated with $0.02 \mathrm{mM}$ mercuric chloride, $0.3 \mathrm{mM}$ methylmercuric chloride, $1.0 \mathrm{mM}$ N-ethylmaleimide and PBS (control) at $37^{\circ} \mathrm{C}$. Concentration of erythrocytes was $2.0 \%$. After the washing with PBS and lysis with hypotonic buffer, sulfhydryl groups in the nembrane were measured.

$\mathrm{HgCl}_{2}, \mathrm{MMC}$ and NEM, several additional protein bands were found in the range of 90,00040,000 of molecular weight (Fig. 2). However, when the hypotonic lysed membrane was treated with those chemicals, the additional bands were not observed (Fig. 3) and there was a close relation between desiruction of erythrocytes and appearance of those additional bands (Fig. 4).

In the membrane produced by PCMB, the number of protein bands in the range of $90,000-40,000$ of molecular weight was less than in the membrane produced by $\mathrm{HgCl}_{2}$ and MMC. When the hypotonic lysed membrane was treated with PCMB, a new protein band appeared under band IV suggesting the separation of band IV with PCMB.

A large amount of protein was obtained from membranes of erythrocytes lysed by $\mathrm{HgCl}_{2}, \mathrm{MMC}$ and NEM compared with those lysed by PCMB or the hypotonic buffer. It is possible that the additional bands localized between 90,000 to 40,000 of molecular weight, are the result of binding of protein present in erythrocytes to membranes and/or inhibition of elution of membrane protein. Carter (7) demonstrated that protein of hypotonically obtained membranes was extracted with $p$-chloromercuribenzenesulfonate as with $5 \mathrm{mM}$ phosphate buffer at $37^{\circ} \mathrm{C}$ and with NEM extraction of protein was inhibited.

Membranes produced by saponin, lysolecithin, digitonin, and Triton X-100 showed a different electrophoretic pattern of protein from that of mercurial lysed membrane thus indicating different effects on membrane protein. The affinity of mercurials for $\mathrm{SH}$ in erythrocyte membrane was studied. SH decreased by treating erythrocytes with mercurials 
and NEM, and the degree of SH was not related to the hemolytic potency (Fig. 6). However, $\mathrm{SH}$ in the membrane, produced by hypotonic lysis and treated with mercurials, was parallel to the hemolytic potency. Therefore, it is assumed that the degree of SH in membrane is not absolutely required for induction of lysis of erythrocytes but that $\mathrm{SH}$ in the membrane is inhibited considerably by mercurials.

\section{REFERENCES}

1) TANAKa, R. AND NAKAI, K.: Hemolysis and morphological changes in rat erythrocytes with mercurials. Japan. J. Pharmacol. 27, 413-419 (1977)

2) TANAKA, R., OHMIYA, Y. AND NAKAI, K.: Deformation of surface structure of erythrocytes induced by mercurials. J. Toxicol. Sci. 1(2), 58-59 (1976)

3) Lowry, O.H., Rosebrough, N.J., Farr, A.L. ANd Randall, R.J.: Protein measurement with the Folin phenol reagent, J. biol. Chem. 193, 265-275 (1951)

4) Fairbanks, G., Steck, T.L. ANd Wallach, D.F.H.: Electrophoretic analysis of the major polypeptides of the human erythrocyte membrane. Biochemistry 10(13), 2606-2617 (1971)

5) Sedlak, J. ANd Lindsay, R.H.: Estimation of total, protein-bound, and nonprotein sulfhydryl groups in tissue with Ellman's reagent. Analyt. Biochem. 25, 192-205 (1968)

6) Sтеск, T.: The organization of proteins in the human red blood cell mombrane. J. cell Biol. 62, 1-19 (1974)

7) CARTER, J.R.: Role of sulfhydryl groups in erythrocyte membrane structure. Biochemistry 12, 171-176 (1973) 